\title{
Design and Fabrication of Cantilever MEMS Sensor Model for Electro-Chemical Gas Sensor
}

\author{
Guruprasad B \\ Electronics and Communicationl Department, \\ Vishveshvaraya Technological University \\ Mysore College of Engineering \\ Mysore-570028,India
}

\author{
Shwetha M.S \\ Material Science and Engineering Department, \\ JSS Science and Technology University \\ Sri Jayachamarajendra College of Engineering \\ Mysore-6, India
}

\begin{abstract}
The exponentially rise in technologies have broadened the horizon of human life to exploit enhanced systems and solutions to make precise, timely and optimal decision. Undeniably, majority of the scientific contributions intends to make human society and allied industrial activities productive and efficient. The up-surging industrial development and complex operating environments, especially chemical industries, strategic warehouses or infrastructures where there can be the presence of different gases in direct or indirect form, demands a robust and efficient sensing solution to avoid any unexpected hazardous. Considering the significance of a robust and efficient gas sensing technology, in this manuscript the predominant emphasis has been made on exploring different technologies and allied mechanisms to perform gas sensing. Being a survey paper, in this paper key gas sensing technologies, including cantilever based Micro-Electro-Mechanical System (MEMS) have been studied. Observing majority of the researches, it can be found that cantilever MEMS can be the potential solution for gas sensing and analytes identification in a complex operating environment. However, the design, shape and materials of the cantilever MEMS often decides efficacy to perform sensing. This survey revealed that to achieve optimal gas sensing solution, enhanced semiconductor cantilever design with optimized shape, and materials can yield sensitive and power efficient gas sensing solution. Considering the fact that the shape and materials have the combined impact on overall efficiency, certain machine learning approaches such as Artificial Neural Network or even enhanced algorithms can be considered. Obtaining an optimal solution with suitable materials, shape and size of cantilever which can be stated to be a NP-hard problem, machine learning or stochastic prediction models can also be considered. Structurally, the optimal setup with Piezo-resistive cantilever MEMS with optimal shape, size and coating material can enable optimal gas sensing performance of the micro-cantilever structure. Moreover, the selection of coating materials can help achieving deflection sensing or surface strain to perform flow rate assessment.
\end{abstract}

Keywords- Micro-Electro-Mechanical Sensor, CantileverMEMS, Machine Learning, Gas sensor, Flow Rate Analyzer

\section{INTRODUCTION}

The exponential rise of the toxic gases and chemicals released by the various field such as manufacturing industries, transportation, production of numerous daily commodities as medicine, cosmetics, hygiene and care products, and pharmaceuticals has a more impact on the environment. Furthermore, such industrial progress had to pay a high price on the quality of the environment in terms of atmosphere, soil and water pollution, climate changes induced by human activities, deforestation and contribution to global warming. In addition, such operating environment where even there can be the presence of human being, detecting gas and its concentration is inevitable [1]. The identification of gas (es), chemicals as well as volatile organic components is inevitable in numerous applications. Over the last decades, gas detection instrument have been designed to monitor the working atmosphere of the various toxic gases to assist different application areas such as safety, medical diagnosis, pollutants detection and transportation industries [1]. The qualitative and quantitative detection of the gas mixture play a vital role in the field of environmental protection, industrial control and poison gas alarm. To overcome the above problem there is a necessity of development of easy-to-use, portable, miniaturized, and robust chemical micro-sensor arrays with distributed partial specificity and the designed sensor should be capable of real time, on line and continuous monitoring in a specific process. Various physical and chemical principles are involved in the qualitative and quantitative analysis of various toxic gases detection [2]. In addition there are different types of gas sensors used to identify the gases such as photo ionization sensors [2-4], infra red sensors [5], fluorescent sensors [6-8], metal oxide semiconductor [9], catalytic gas sensors [10] and electrochemical gas sensors [11]. Among all these electrochemical gas sensors is widely used approach [11].

The identification of different gas species with polluting effects like carbon monoxide, hydrogen sulfide, nitrogen and sulfur oxide and ozone is challenging task worldwide because of their complex and destructive effects on the environment. In addition, the low concentration values of these species are involved with risk towards human health and damage to ecosystem. The detection of such kind various gas species and concentration can be achieved by using electrochemical sensor because it needs significantly less power to operate. In fact, the power consumption is also low for this sensor as compared to all other available sensor for gas monitoring. Therefore, the electrochemical sensors are widely employed 
in portable devices that contain multiple sensors. Also this is the most popular sensor in space application [12]. There are "Four S" requirements can be created and related with chemical sensing namely, Sensitivity, Selectivity, Stability and Speed of response. Recently, sensor technologies has evolved significantly towards achieving high reproducibility, robustness, simple structure and low electricity consumption in detection of various gaseous species and concentration over wide range of application [13]. Electrochemical gas sensors are highly sensitive, low power consumption and have good specificity towards target gases. Miniaturization and direct linear output of current to gas concentrations are the other advantages of the electrochemical gas sensors. The sensitivity, accuracy and linearity of the electrochemical sensors are independent of size. Moreover, the sensitivity depends on the number of reactive sites of the electrode as well as size of the gas inlet [12]. Electrical signals are generated in response to the chemical reaction in electrochemical sensors. In electrochemical sensors, the reactions typically depend on the surface area of the electrodes. Increasing surface area of the electrode provides higher reaction sites often leads to the increasing size of the sensor. To obtain a small size sensor with high electrode surface area for electrochemical reaction it is necessary to increase the surface area to volume ratio; however varying the surface can have decisive impact on the overall detection efficiency. To meet these criteria there is a need of nanoporous structures that are becoming a popular in realizing a high surface area with respect to the small size of the sensor. MEMS technology has been identified to achieve most of the ideal requirements to realize nano-porous structures because the MEMS technology provides the accommodation of scaling laws, for example advanced process technique like Atomic Layer Deposition (ALD) is used to fabricate the nano-porous structure [14].

In the last few years numerous research groups have introduced the use of micro-sensor arrays in various applications namely, metal oxide semiconductors, electrochemical sensors, conducting polymers, quartz crystal microbalance devices, field effect transistor devices and hybrid sensor arrays characterized by different sensing application [15]. Moreover the concept of multi-sensor array has been developed with micro-cantilever transducers [16]. Micro-cantilevers are the most simplified device based on MEMS technology. Recently, improved micro fabrication technology and nanotechnology have been introduced to develop the tiny structure sensors. Three decades ago established an ultra precise position sensing with novel imaging technique called atomic force microscopy to achieve topography resolution on atomic scale. This can be obtained by raster-scanning the surface using micro-fabricated cantilever beam. Other than imaging the high force sensitivity is used for the measurement of surface forces which occur during the mechanism of molecule adsorption on surface of the cantilever, thus enabling the cantilever to act as chemical sensors. Cantilevers offer fast and reliable detection of gases and small concentration of molecules in mixture of gas or solution [17]. Moreover the researchers have been explored the various different application of the micro-cantilevers in the field of sensors. These sensors offer high sensitivity, low cost, simple procedure, less analytes requirement, non hazardous procedure and quick response with conventional analytical techniques. In detection and identification of complex chemical, micro-cantilevers are the best choice for use in the large multi-sensor arrays because of its low cost, smaller size and mass sensitivity. Different semi selective detectors have been designed in chemical multi-sensor array for the detection of large variety of chemical vapors. To address this, researchers have coupled these multi-sensor arrays with distributed selectivity's towards different analytes or classes of compounds with chemometrices and pattern recognition techniques to interpret the complex sensor signals and provide automated decision-making capabilities. The array essentially recognizes the chemical fingerprint, which is the chemical information of the sample or classes of samples to be recognized. Sensitivity and selectivity are the important characteristics in enhancing the overall performance of the sensors. The distributed selectivity is achieved with respect to material coating variation of cantilevers and similarly the distributed sensitivity is obtained with respect to dimensions variation of the cantilever structure like length, breadth and thickness.

Nowadays, substance analytes are assuming extremely fundamental part in all applications, particularly biomedical, as in breath-gas monitoring where highly sensitive volatile organic compounds (VOC) detection by chemical or gas sensors enables new applications of human monitoring system, industrial chemical hazard prevention etc,. Hence it is important to distinguish the analyte species and concentration. Many researchers utilized different material coatings for the cantilevers for the individual identification of analyte species and concentration in gas mixture [19-23]. The different sensors developed so far for identification of analytes species and concentrations are unstable in numerous applications [23]. Therefore identification of different analyte species and concentration in gas mixture is vital. It can be achieved by integrating number of sensors in arrays and combining the data from the sensor array, which can further be processed with machine learning model to get optimal design and allied performance. Pattern recognition is the technique used to solve the problems like classification encountered in the physical and engineering sciences. Recently, gas sensors are developed for the identification or classification of gases and gas mixtures or odors employing gas sensor arrays through pattern recognition technology [18] to achieve high selectivity in identification of target gases. (Introduction)Moreover, pattern recognition algorithms have become very critical component towards successful establishment of chemical sensor arrays because no single pattern recognition algorithm can meet each of the requirements. To design chemical sensor array, many researchers applied pattern recognition techniques basis on either linear discriminant analysis [19-21], principal component analysis [22, 23] or Artificial Neural Networks (ANN) [24]. Poorly chosen or designed pattern recognition algorithm leads to the lower reliability and an increase number of false alarms therefore the choice of the pattern recognition algorithm is very critical in the application of chemical sensor array. Moreover, the identification of chemically similar species is difficult with poor choice of 
pattern recognition algorithm. The establishment of these coupling sensors structure is straightforward in the controlled environment of the laboratory because here major interference are controlled or known, but additional challenges are required in the field measurements in order to detect and identify the target analytes with high concentrations of interfering species. The application of chemical sensor system with pattern recognition technique has unique set of requirements and consists of fast classification accuracy, simple training method and low memory requirements, also robust to outliers and measurement of the classification of uncertainty [25]. Among all the pattern recognition techniques, ANN based approach is best choice for the detection and identification of the complex data because it produce the more accurate classification [26]. ANN is obtained from numerous simulated neurons which are connected same way as the human brain's neurons therefore it has a capable of learning in a similar manner as humans [27]. ANN's consist of highly interconnected group of neurons that process information in parallel. Considering the significance of a robust gas sensor design using MEMS technologies, in these survey paper different approaches developed so far with their efficacy and limitations are discussed. Realizing the robustness of cantilever MEMS model for gas sensing solution, different design artifacts and allied constructs are discussed in this paper. This discussion can help achieving an optimal cantilever MEMS design for gas sensing and analytes assessment.

The remaining sections of the presented manuscript are as follows. Section II discusses the related works pertaining to MEMS based gas sensor, cantilever MEMS designs for sensing purposes, etc. The overall conclusion and inferences are presented in Section III. References used in this manuscript are given at the end of the manuscript.

\section{RELATED WORK}

This section primarily discusses some of the key literatures pertaining to fabrication of MEMS based electrochemical gas sensor for the identification of analytes species and concentration.

authors [28] designed a MEMS infrared spectrometer to classify gases with infrared absorption spectroscopy. Authors found that their approach is simple and even offers identification of nonreactive molecules like CO2. Authors [15] applied thermoelectric MEMS sensors to detect and identify gas mixtures like $\mathrm{CH} 4, \mathrm{C} 2 \mathrm{H} 6, \mathrm{~N} 2$ and $\mathrm{CO} 2$ with TMultivariate data analysis technique. This approach was found low cost solution to detect natural gases at different temperature. A similar effort was made in [29], where to identify mixed gases along with natural gas, ethanol and butane, machine leaning model named Artificial Neural Network (ANN) was applied. Noticeably, ANN pattern recognition technique was applied to perform classification in conjunction with the micro-cantilever array gas sensor, where each micro-cantilever surface was fabricated with different material sensing layers. Author [30] developed a MEMS based cantilever type micro-heater array using four distinct isolated micro-heaters on single die for volatile and toxic gas detection. Similar to [29], to identify the individual gas and concentration in gas mixture author [21] uses ANN pattern recognition technique to develop an integrated micromachined gas sensor array which uses various organic sensitive films namely $\mathrm{SnO} 2, \mathrm{TiO} 2, \mathrm{ZnO}$.

Authors in [31] focused on the performing qualitative and quantitative method based target analyte detection in the gas mixture. To achieve it, authors applied two key parameters such as localization degree $\mathrm{Xk}$ and norm of normalized eigen mode shifts $|\Delta \mathrm{u}|$ and derived a new method for identification of two different analytes with coupled three-cantilever array. In [32] a cantilever-based bio-chemical sensor was developed for simultaneous detection and analysis of two samples. Here, sensor implemented in conjunction with the micro liquid handling system. In addition, surface stress sensor was designed in such manner that it employs piezo-resistive cantilever and sensor fabrication which was obtained by means of conventional fabrication and cantilever offer piezoresistive readout method. Authors [33] designed a spectrometric sensor based on MEMS to be used for measuring dissolved $\mathrm{CO} 2$ concentration by means of an analyzer using $\mathrm{CO} 2(\mathrm{aq})$ calibration samples obtained from various $\mathrm{NaHCO} 3$ concentrations in solution. Unfortunately, authors failed to address the concentration of different components. Considering this fact, authors [34] proposed chemical sensors based on cantilever array, which was armored with ANN algorithm for analysis of multiplexed response of the cantilever array with synthetic responsive phases. This approach offered identification of individual analytes and binary mixture. In addition, it enabled identification of the concentration of individual components in a mixture. To achieve detection of gas vapor and linear response to concentration levels authors [20] applied micromachining technology by means of conductive polymer-carbon black composite films. Authors applied the film structure to be used for a miniature polymer-based chemical gas sensor array developed on silicon substrate. To identify various gasses including $\mathrm{H} 2, \mathrm{NH} 3$ and $\mathrm{C} 2 \mathrm{H} 5 \mathrm{OH}$ at low concentration author [35] proposed a MEMS gas sensor with gas detection circuit which was especially designed using CMOS technology to offer wide measurement range and high resolution. Author [1] designed and fabricated MEMS Resettable Circuit Breaker, where cantilever material was selected as SOI wafer device silicon layer, while heater material employed platinum. For bonding trace and electrostatic electrodes chrome gold was taken into consideration. However, authors failed to address the electrostatic actuation and steady performance.

Observing the above stated discussions, it can be found that cantilever MEMS solutions can be of utmost significance towards gas sensor development. However, the design, material, and shape of the cantilever has direct impact on it efficacy. Considering this fact, the following section discusses some of the key literatures pertaining to Cantilever MEMS design for gas sensing purposes.

To enable ultrathin, low stress and ultra high sensitivity authors [23] applied Merged Epitaxial Lateral Overgrowth (MELO) of Silicon and Chemical-Mechanical Polishing 
(CMP) to design a new method for surface micro-machined thin single-crystal silicon cantilever beam. In [36], authors developed a MEMS cantilever on SOS with fabrication tools. Optical attenuation demonstration was achieved with the physical micromachining and UV laser direct writing by actuating the cantilevers, where optical waveguide presented in each cantilever. To achieve device self-actuation with low driving voltage, device self-sensing with low power consumption and to harvest energy in the field of wireless sensor network (WSNs), authors [9] proposed a piezoelectric MEMS device with incorporation of Piezoelectric Lead Zircontetitanate (PZT) thin films. To obtain low power SPM (Scanning Probe Microscopy) data storage system, authors [24] used integrated heater and piezoelectric sensors with silicon cantilever to design a Micro cantilever to achieve read back signal with grating of $30 \mathrm{~nm}$ depth. Unlike classical machine learning or pattern analysis based detection, authors [5] applied evolutionary computing algorithm named Genetic Algorithm (GA) to augment performance of MEMS unimorph piezoelectric harvesters. Moreover, to achieve high voltage efficiency authors [5] applied an automated design and optimization concept that enabled higher conversion efficiency T-shaped unimorph MEMS harvester. For the low power consumption application such as bistable switching relay author [37] proposed a bistable MEMS from torsion/cantilever beam system. The detail study of array design considerations of the MEMS vibration energy harvester basis on cantilever structure is developed by the authors [38] to achieve high energy and to reduce the size of the cantilever with three different design of wideband cantilever based structure MVEH

To enhance sensitivity, authors [22] proposed a high sensitivity rectangular piezo-resistive cantilever model with monolithic integration applying CMOS circuits that eventually augmented the response signal of piezo-resistive cantilever. Eventually, authors achieved the enhancement in the displacement sensitivity of the piezo-resistive cantilever by measuring the cantilever sensitivity. In [19] a trace gas detection sensor was developed by applying thermal driving and piezo-resistive sensing MEMS cantilever resonator, which was analyzed using Finite Element Analysis (FEA) to get optimal configuration of the resonator to be more effective towards sensitivity and efficiency. This model was found efficient in achieving temperature uniformity. To enhance sensitivity, authors [39] used integrated electrothermal nano-lip and piezo-resistive sensor to propose the micro cantilever-lip silicon probe-array for MEMS highdensity data storage. Similarly, to enhance the sensitivity of fluid speed authors [40] proposed MEMS based cantilever flow sensor which was used to identify the surface strain on cantilever that often occurs due to mass flow. In their proposed model [40], authors used INTELLISUITE software as FEA tool to analyze the operating mechanism of strain beam in flow sensor. Unlike conventional sensor design, to detect humidity and temperature authors [41] applied $\mathrm{Cu}$ and polysilicon as sensing material to design MEMS cantilever. Similarly considering the application areas like environmental monitoring, electronics, agriculture and biomedical field authors [42] developed a humidity sensor based on MEMS cantilever applying $\mathrm{T}$ shaped micro cantilever having various sensing materials namely Al2O3, Porous Silicon and Poly Silicon. Authors applied INTELLISUITE Ver. 8.7 for FEA. To enhance the sensitivity of the picogram order mass sensing authors [43] developed a mode-localized cantilever array model by assessing sensitivities of various cantilever structures. To achieve high sensitivity authors [44] developed a diversified microcantilever structure using micro-bending measurements techniques. Authors made use of a simple optical IR emitter/receiver array and point of contact approach to design sensor. Similarly by applying the process of in-house surface micromachining with structure of amorphous silicon sacrificial layer authors [6] fabricated a new Radio Frequency (RF) MEMS structure on quartz wafer to facilitate minimum temperature dependent permanent deformation.

Authors [45] used loading/force effect to implement Half Cut Stress Concentration (HCSC) region on MEMS piezoresistive cantilever surface with increase in stress on the cantilever surface. To achieve better resonance frequency for multiple mass sensing authors [46] developed a cantilever based MEMS by applying different cantilevers in an array setup with monolithic integration using CMOS technique. Applying the surface profiler and laser vibrometer authors [47] developed an optical workstation with static and dynamic tests to characterize fabricated devices with the piezo and electrostatic actuation. Considering the need to address response time authors [48] proposed a U-shaped and rectangular piezo-resistive cantilever array by using silicon micromachining technology. Authors applied piezo-resistive material using single crystalline silicon. Similar effort was made in [49] where authors proposed an array based autonomous instrument comprising 8 MEMS micro cantilevers.

As discussed in above literatures, a significant effort has been made towards employing semiconductor materials for cantilever MEMS design, however in practice during the phenomena of measuring the gas mixture the semiconductor gas sensors suffer from the cross sensitivity. To alleviate such issue authors [50] focused proposed a detection system using LabVIEW. They designed MEMS sensor array comprising four array MEMS gas sensor to enhance response of gas detection along with better sensitivity. Author [11] proposed a method to detect the single nucleotide polymorphisms (SNPs) with MEMS. They targeted on mitigating the fluidic control operation with single-chamber micro-fluidic device comprising polymerase chain reaction (PCR) and single base extension (SBE) on micro-beads. In [51] a new wafer-scale micromachining technology with 3 -D cantilever array was developed by applying micromachining technology of metal film. This method employed vertically $\mathrm{Si}$ metal laminated structure that operates at in-plane mode and thus facilitates easy-to-package, non-stiction and compact. Considering the method of thermo-anemometric and calorimetric measurement, authors [52] presented an experimental analysis of thermal MEMS sensor with the help of gas flow velocity sensor. The designed sensors performed signal processing in conjunction with an analog circuit model. Authors [53] applied card's second law of energy as well as Hook's law to obtain the elasticity coefficient of the 
cantilever to obtain a closed X-type MEMS cantilever model. In [54] focus was made on detailed study of two types of cantilever beam with different characteristics by varying Silicon, Silicon dioxide and polysilicon materials. Varying above stated materials, authors analyzed the natural resonant frequencies or eigen frequencies of the beams with different beam thickness.

In [55] four different structures of flow sensors namely the rectangular membrane cantilever beam array structure, the trapezoidal membrane cantilever beam array structure, the inverted trapezoidal membrane cantilever beam array structure and the triangular membrane cantilever beam array structure were developed. Authors [55] found that the inverted trapezoidal membrane cantilever beam array structure is the best that in conjunction with a MEMS-based flow sensor can be vital for gas identification. However this approach is highly expensive. In [56], authors applied single magnetic actuator and a single photo detector for concurrent detection to develop Parallel readout of a micro-cantilever array to estimate thermal resonance peaks of inherently frequency-multiplexed MEMS cantilevers. Applying Grated Waveguide (GWG) authors [57] designed an optical read-out model to assess micro-cantilever sensor arrays and their performance. Authors performed optical system analysis with Fabry-Perot interferometer; where they found a lossy cavity in between cantilever and GWG. The formation of resonant cavity was done by placing a diffraction grating in $\mathrm{Si}$ waveguide below a cantilever arm which as a result enabled noise reduction on an optical signal. Authors [58] used optical read-out technology to propose a micro-machined cantilever sensor array. To reduce stress gradient in cantilever beam, authors [1] designed $\mathrm{Ni}-\mathrm{Fe}$ freestanding microcantilever structure that enabled implementation of perm alloy cantilever structure in magnetically actuated MEMS switches. ANN based structural optimization effort was made in [59], where authors used ANN for MEMS diagnosis and BLACK-box modeling of non electronic part without using concurrent algorithm and parallel computation. In addition, ANN was applied to design a lumped model of capacitive transducer to be used for sensing. In [60], authors developed an Efficient Reliability-Based Design Optimization for MEMS using Sigma-Point concept which offer the output variance calculation in accurate.

Authors [61] developed a large silicon cantilever structure of $30 \mathrm{~mm} \times 30 \mathrm{~mm} \times 8 \mathrm{~mm}$ dimension to detect resonances. Additionally, they exploited the benefits of the localized thermal expansion in piezo-resistors placed near the cantilever to obtain temperature gradient to be used for actuating the cantilever at its resonance frequency. Authors recommended the deflection sensing of the cantilever by applying piezo-resistors. Authors [62] designed cantilever MEMS with gold which is capacitively coupled to microstrip lines for mechanical trimming of high-frequency oscillator circuits to get higher sensitivity. Similarly a micromechanical membrane switches was developed in [63], where authors applied cantilever model with silicon. Authors stated that the cantilever model should have filled gap between silicon transistor and mechanical electromagnetic relays. In [64], authors introduced the nerve agent detectors with cantilever model. They [64] applied a hygroscopic material like phosphoric acid or gelatin to coat the cantilever surfaces that enabled sensing of the water vapor with pictogram mass resolution. Noticeably, authors applied beam deflection technique with modified AFM electrons to estimate the deflection of the individual cantilevers.

In practice, the response of single cantilever sensor suffers from thermal drifts or unspecific adsorption. To overcome this problem cantilever array including reference cantilevers can be taken into consideration. Considering it as motive, authors [65] reported the first use of cantilever array. The use of micro-fabricated cantilever as a sensor for AFM has become more frequent [66]. In [67], authors designed piezoresistive deflection readout approach by developing the cantilever with thin film of Zinc oxide. Authors found their model effective for the optical beam deflection readout. Realizing the fact that the nanogram changes in mass loading often takes place when small particles are deposited onto AFM probe tips, authors [68] developed a model to track cantilever resonance frequency to retain better performance. In [69] authors reported that the static bending and resonance frequency of micro-cantilevers can be significantly influenced by ambient condition of moisture adsorption. In addition, the deflection of cantilever can also be influenced by thermal effect. Considering these facts, to identify the chemical reaction with high sensitivity authors [70] developed a static cantilever bending method. A significant research by [71] reported that the resonance frequency can change due to adsorption of analyte vapor on exposed surfaces. In addition, the frequency can also vary due to the mass loading and adsorption-induced changes in cantilever spring constant.

Author [72] made use of the cantilever structure to analyze the adsorbate-induced surface stress. In [73] gold cantilever was designed where it was found that the induced surface stress occurs due to adsorption of alkanethiols. The high affinity leads to fast bending response within minutes. The dynamic mode analogy to the technique of non contact of AFM was described in [68] where authors recommended cantilever to be oscillated at its resonance frequency. Tiny tungsten particle spheres were mounted at the cantilever apex to estimate mass changes from shifts at the cantilever resonance frequency. Typically, in addition to the adsorption effect, thermal effect too produces the cantilever bending. The heat generated on the surface of the metal coated cantilever often causes bending. This bending phenomenon is called bimetallic effect. In this relation, authors [70] took advantage of this effect to introduce the heat mode to develop miniaturized calorimeter offer pico-joule sensitivity. The operating modes relies on the physical effects like heat generation from the absorption of light by materials deposited on the surface of the cantilever [63] or bending of cantilever with respect to electric or magnetic forces. The sensitivity of the cantilever heat mode is higher than that of traditional calorimetric approaches performed on milligram samples. The cantilever heat mode uses nano-gram amounts of sample to offer nano-joule [74], pico-joule [75], and femto-joule [76] sensitivity. 
Recent researches [77] found that diamond can be a potential alternative for the development of resonant microcantilever because of its robustness, hardness, biocompatibility and exceptional mechanical and thermal properties. Authors in [77] proposed resonant sensor with polycrystalline diamond where the high elasticity modulus (in the order of $103 \mathrm{GPa}$ ) enabled it to be used for flow analyzer. In later researches, [78] it was found that diamond is suitable for stable grafting of a wide range of bio-receptor with covalent $\mathrm{C}-\mathrm{C}$ bonding because of its carbon nature; however the calibrated design and coating is must to be used as sensor. There are different types of coating material used to augment the chemical sensitivity of the cantilever. Silicon microcantilevers can be used as a chemical sensor because their surface acquires high affinity towards target analyte [79]. It is necessary to apply metal coating layers to enable surfaces as biological or synthetic receptors [79][80]. Such cantilevers can be used to identify the gases like hydrogen and mercury with palladium and gold coatings, correspondingly [81][82]. To enhance the sensitivity of the cantilever, authors [83] designed a micro cantilever with silicon and diamond based on MEMS technology. To enhance the sensitivity, response time and velocity measurement time, recently authors [84] recommended using the MEMS technology to deposit platinum layer onto silicon nitride layer which can achieve better piezo-resistor to be used as micro-scale air flow sensor. Authors [84] applied free-standing cantilever structure to be used for air-flow sensor.

In [88][89] authors applied four methods including film deposition, photolithography, etching and doping for the micro-fabrication of silicon based cantilevers. In addition, authors designed a combined model using these approaches together to achieve multiple cantilever chips with desired shape and mechanical properties. Authors [90][91] fabricated a polished mono-crystalline wafer of Silicon on Insulator (SOI) to be used for cantilever design. In [92], authors proposed SOI wafer comprising thick bottom layer with single crystal silicon, middle layer with silicon oxide and top layer with single crystal silicon or silicon nitride. Authors [90-92] found that the SOI wafer can be significant in the fabrication process. They proposed oxide layer acting as an etch stop while the thin top layer of single crystal silicon (or silicon nitride) was applied as material for the actual cantilever design. It reveals that it is must to reduce defects in thin-top layers to get higher sensitivity. The shape of the cantilever too has impact or relation with the overall performance, especially towards gas and chemical detection [85]. With this motive, to enhance the sensitivity authors [85] applied the square pads at the end of the cantilever beams that enabled the measured capacitance proportional to the surface area of the parallel plates. Rectangular, paddle and T-shaped cantilevers are common in the field of optical detection. The surface-stress induced curvature is not uniform in all cases. This is because the cantilever beam is clamped on one end that forces beam to twist [86]. Realizing this issue, authors [87] developed " $T$ " shaped cantilever design that enables the major part of the beam to be mechanically decoupled from the twist-inducing stress at the clamped end. The fabrication of micro-cantilever can also be achieved by applying polymer possessing readily tailorable mechanical and chemical properties. Modified stiffness of silicon can also be achieved to design cantilever by changing the geometry or applied rigid coating at the surface. Since, stiffness of the polymeric cantilevers employs merely a change in material and therefore different properties can be obtained with same geometry of cantilever. The polymer based cantilever can significantly reduce the manufacturing cost as well as the apparatus dimensions used for the detection [93]. The materials applied for the polymer based cantilevers span a wide range of thermisters, thermoplastics and polymeric composites. In [91], authors recommended using polymer composites comprising silver nanoparticles and SU-8 while in [95] the carbon nanotubes, poly (m-phenylenevinyleneCO-2, 5-dioctoxy-p-phenylenevinylene) and many other combinations were reported to be used for cantilever design. Authors [96-98] suggested using a SU-8 cantilevers with arrays for optical layer and piezo-resistive [99][100] detection. Authors [96] compared the deflection of silicon nitride cantilevers to SU-8 cantilevers with similar dimensions.

Thin-film coating has always been found potential to increase sensitivity. The deposition of thin film on to the wafer was achieved by the spin coating for the formation of polymer thin film where authors recommended using either Chemical vapor deposition (CVD) or physical vapor deposition (PVD) and electroplating [93]. Authors [88][89] used the CVD to deposit silicon oxide and silicon nitride layers as insulation, masks and etch stop in cantilever design. Authors applied gaseous reactants in CVD into the vacuum chamber with heated wafer substrate and thus the CVD films formed varies in thickness from 20-1500 nm depending upon deposited material [88]. Additionally, authors [88] introduced the PVD methods such as sputtering and evaporation for metals deposition on cantilever electrodes. In this PVD process a thin film accumulated the substrate from a heated reservoir of material in a linear alignment. Also metal deposition was performed by means of electroplating. Metals were used as reflective surfaces, electrode material, electronic interconnects, thermistors, and chemically reactive binding sites (because alkanethiols covalently bind to gold).

Researchers [101] found that the Pd-coated cantilever sensor can be efficient to detect hydrogen. Authors [101] proposed cantilever design to report bulk adsorption of hydrogen into palladium with differential stress formation which leads film expansion. Cantilever bending relies on the thickness of $\mathrm{Pd}$ film and is reversible. In addition, its magnitude is proportional to hydrogen partial pressure. Authors [102] designed a MEMS based hydrogen sensor with an array of 10 micro-machined cantilever beams. Authors [102] performed deflection estimation with capacitive approach, where the sensitive coating comprises $90 \% \mathrm{Pd}$ and $10 \% \mathrm{Ni}$. Their proposed model was found effective to detect concentrations of $0.4 \%$ hydrogen. Similar to [101], authors in [103] proposed a micro-cantilevers sensor coated with Pd for hydrogen detection and found that the shape and surface roughness of the cantilever has vital impact on overall sensitivity. Additionally, they found that the surface stress response depends strongly on the hydrogen dissociation into the bulk of the Pd layer. Similarly, authors [104] developed 
resonating cantilever sensors to determine the hydrogen storage Capacity of Carbon Nano-tubes (CNT). Authors found that the storage capacity of $6 \%$ and the mass resolution of the order attogram. Similarly, to detect Freon with concentration of $10 \mathrm{ppm}$ authors [105] developed a self excited piezoelectric micro-cantilevers using MFI zeolites layer. Authors [106] proposed a SiO2 coated Si3N4 microcantilever to detect $\mathrm{HF}$, a decomposition product of nerve agents. Detection of HF on the basis of etching of $\mathrm{SiO} 2$ was obtained in the range from 0.26 to 13 PPM.

To detect carbon monoxide authors in [107] developed a piezo-resistive cantilever with nickel-containing polyethylene oxide (PEO) layer. Authors [108] developed a piezo-resistive micro-cantilever sensor to detect Hydrogen Cyanide (HCN) with the concentration of 150 PPM. HCN was obtained by reacting KCN with sulfuric acid. Similarly, authors [109] developed a NEMS piezo-resistive cantilever to assess the behavior and response on the basis of the different types of material coatings and analytes. Authors used combination of materials coating like poly-vinyalpyridine and 6mercaptonicotinic acid in conjunction with the different analytes like ethanol and Acetaldehyde. Authors concluded that ethanol with permeable 6-mercaptonicotinic acid (6MNA) nano-cantilever gives better resistance. In [110] authors proposed U-shaped and rectangular MEMS based triple coupled cantilevers. Applying COMSOL Multi-physics and U-shaped MEMS cantilever of $100 \mu \mathrm{m} \times 20 \mu \mathrm{m} \times 2 \mu \mathrm{m}$ produces high displacement and better thermal response in comparison to the rectangular MEMS cantilever. In [111] authors designed different kinds of MEMS based microcantilevers shapes and assessed their impact on sensing sensitivity using ANSYS software. Authors found that the trapezoidal design micro-cantilever can have significant sensing advantages in comparison to the other remaining micro-cantilever shape. A snippet of the different researches made and their methodological paradigm and goals are depicted in Table I.

TABLE- I DIFFERENT RESEARCHES AND ASSOCIATED METHODOLOGICAL PARADIGMS

\begin{tabular}{|c|c|c|c|c|c|}
\hline Author & Proposed system & Technology & Materials used & Target gases & purpose \\
\hline Ying et al [19] & $\begin{array}{l}\text { Thermal driving and } \\
\text { piezoresistive sensing } \\
\text { MEMS cantilever }\end{array}$ & $\begin{array}{l}\text { Finite Element } \\
\text { Analysis (FEA) }\end{array}$ & & & $\begin{array}{l}\text { enhancement in sensitivity and efficiency } \\
\text { and provide temperature uniformity }\end{array}$ \\
\hline Zee et al [20] & $\begin{array}{l}\text { Miniature polymer- } \\
\text { based chemical gas } \\
\text { sensor array }\end{array}$ & $\begin{array}{l}\text { micromachining } \\
\text { technology }\end{array}$ & $\begin{array}{l}\text { polymer-carbon } \\
\text { black composite } \\
\text { films }\end{array}$ & & unique detection of gas vapor \\
\hline El-Din et al [21] & $\begin{array}{l}\text { Integrated micro- } \\
\text { machined gas } \\
\text { array }\end{array}$ & $\begin{array}{l}\text { ANN pattern } \\
\text { recognition } \\
\text { technique }\end{array}$ & $\begin{array}{l}\mathrm{SnO}_{2}, \mathrm{TiO}_{2}, \mathrm{ZnO} \text { or } \\
\text { organic } \\
\text { films }\end{array}$ & & $\begin{array}{l}\text { Identification of individual gas and } \\
\text { concentration in gas mixture }\end{array}$ \\
\hline Yu et al [22] & $\begin{array}{l}\text { Rectangular } \\
\text { piezoresistive } \\
\text { cantilever }\end{array}$ & & & & High sensitivity \\
\hline Gupta et al [23] & $\begin{array}{l}\text { micro-machined thin } \\
\text { single-crystal silicon } \\
\text { cantilever beams }\end{array}$ & $\begin{array}{l}\text { chemical- } \\
\text { mechanical } \\
\text { polishing (CMP) }\end{array}$ & silicon & & $\begin{array}{l}\text { ultrathin, low stress and ultra high } \\
\text { sensitivity }\end{array}$ \\
\hline Pan et al [29] & $\begin{array}{l}\text { micro-cantilever array } \\
\text { gas sensor }\end{array}$ & $\begin{array}{l}\text { ANN pattern } \\
\text { recognition } \\
\text { technique }\end{array}$ & & $\begin{array}{ll}\text { natural gas, } \\
\text { ethanol and } \\
\text { butane }\end{array}$ & \\
\hline Ghosh et al [30] & $\begin{array}{l}\text { MEMS based } \\
\text { cantilever type micro- } \\
\text { heater array }\end{array}$ & $\begin{array}{l}\text { MEMS technology } \\
\text { and uses } 4 \\
\text { individual isolated } \\
\text { microheater. }\end{array}$ & & $\begin{array}{l}\text { volatile and } \\
\text { toxic gas }\end{array}$ & Ghosh et al [30] \\
\hline Thaysen et al [32] & $\begin{array}{l}\text { cantilever-based bio- } \\
\text { chemical sensor }\end{array}$ & $\begin{array}{lr}\text { Surface } & \text { stress } \\
\text { sensor } & \text { uses } \\
\text { piezoresistive } & \\
\text { cantilever and } & \text { and } \\
\text { conventional } & \\
\text { fabrication is used }\end{array}$ & & & $\begin{array}{l}\text { Simultaneous detection and analysis of two } \\
\text { samples } \\
\text { Cantilever offer piezoeresistive readout } \\
\text { rather than optical readout }\end{array}$ \\
\hline Smith et al [36] & $\begin{array}{l}\text { MEMS cantilever on } \\
\text { SOS }\end{array}$ & $\begin{array}{l}\text { physical } \\
\text { micromachining } \\
\text { and UV laser direct } \\
\text { writing }\end{array}$ & silicon & & \\
\hline $\begin{array}{c}\text { Kalaiyazhagan et al } \\
\text { [41] }\end{array}$ & MEMS cantilever & $\begin{array}{l}\text { INTELLISUITE } \\
\text { tool }\end{array}$ & $\mathrm{Cu}$ and polysilicon & & $\begin{array}{l}\text { high sensitivity } \\
\text { measurement of humidity and temperature }\end{array}$ \\
\hline Nallathambi et al [42] & shaped & INTELLISUITE & Porous & & Hymidity measurement \\
\hline
\end{tabular}




\begin{tabular}{|c|c|c|c|c|c|}
\hline & cantilever & version 8.7 with & $\begin{array}{l}\text { Silicon and Poly } \\
\text { Silicon }\end{array}$ & & \\
\hline Xiaomei et al [48] & $\begin{array}{l}\text { U-shaped and } \\
\text { rectangular } \\
\text { piezoresistive } \\
\text { cantilever array }\end{array}$ & $\begin{array}{l}\text { silicon } \\
\text { micromachining } \\
\text { technology }\end{array}$ & $\begin{array}{l}\text { single crystalline } \\
\text { silicon }\end{array}$ & & Enhancement in Response time \\
\hline Ting et al [50] & $\begin{array}{l}\text { non line detection } \\
\text { system }\end{array}$ & $\begin{array}{l}\text { LabVIEW and } \\
\text { MEMS technology }\end{array}$ & & & $\begin{array}{l}\text { enhancement in response of gas detection } \\
\text { with cross sensitivity }\end{array}$ \\
\hline Tian et al [55] & $\begin{array}{l}\text { Designed four types } \\
\text { of cantilevr namely, } \\
\text { rectangular, } \\
\text { trapezoidal, inverted } \\
\text { trapezoidal } \\
\text { triangular membrane } \\
\text { cantilever }\end{array}$ & MEMS technology & & & $\begin{array}{l}\text { Inverted trapezoidal is the best choice for } \\
\text { detection }\end{array}$ \\
\hline Wilfinger et al [61] & $\begin{array}{l}\text { Piezoresistors } \\
\text { cantilever of } 30 \mathrm{~mm} \times \\
30 \mathrm{~mm} \times 8 \mathrm{~mm}\end{array}$ & & & & Focus on resonance frequency \\
\hline Heng et al [62] & cantilever & & gold & & $\begin{array}{l}\text { for mechanical trimming of high-frequency } \\
\text { oscillator circuits }\end{array}$ \\
\hline Kolesar et al [64] & $\begin{array}{l}\text { nerve agent detectors } \\
\text { with } \quad \text { cantilever } \\
\text { structure }\end{array}$ & $\begin{array}{l}\text { Beam deflection } \\
\text { technique and } \\
\text { AFM electrons are } \\
\text { used }\end{array}$ & $\begin{array}{l}\text { phosphoric acid or } \\
\text { gelatin }\end{array}$ & & \\
\hline Itoh et al [67] & $\begin{array}{lr}\text { Piezoresistive } & \\
\text { cantilever } & \text { with } \\
\text { deflection } & \text { readout } \\
\text { approach } & \\
\end{array}$ & & zinc oxide & & $\begin{array}{l}\text { Also applied for the optical beam deflection } \\
\text { readout }\end{array}$ \\
\hline Berger et al [73] & cantilever & & gold & alkanethiols & $\begin{array}{l}\text { reported the induced surface stress due to } \\
\text { high affinity }\end{array}$ \\
\hline Cleveland et al [68] & cantilever & AFM technology & tungsten & & $\begin{array}{l}\text { to determine mass changes from shifts in the } \\
\text { cantilever resonance frequency }\end{array}$ \\
\hline Possas et al [77] & resonant sensor & & $\begin{array}{l}\text { polycrystalline } \\
\text { diamond }\end{array}$ & & $\begin{array}{l}\text { robustness, hardness, biocompatibility and } \\
\text { exceptional mechanical and thermal } \\
\text { properties }\end{array}$ \\
\hline$[79,80]$ & Micro cantilevers & $\begin{array}{l}\text { MEMS } \\
\text { Technology }\end{array}$ & Silicon & & Gas identification \\
\hline Thundat et al [81] & Micro cantilevers & $\begin{array}{l}\text { MEMS } \\
\text { Technology }\end{array}$ & palladium & Hydrogen & Gas identification \\
\hline Baselt et al [82] & Micro cantilevers & $\begin{array}{l}\text { MEMS } \\
\text { Technology }\end{array}$ & gold & Mercury & Gas identification \\
\hline Maira et al [83] & micro cantilever & $\begin{array}{l}\text { MEMS } \\
\text { Technology }\end{array}$ & silicon and diamond & & To enhance sensitivity \\
\hline Wang et al [84] & $\begin{array}{l}\text { Piezoresistor } \\
\text { cantilever structure }\end{array}$ & MEMS technology & $\begin{array}{l}\text { platinum layer onto } \\
\text { silicon nitride layer }\end{array}$ & & $\begin{array}{l}\text { To enhance sensitivity, response time and } \\
\text { velocity measurement time }\end{array}$ \\
\hline$[90][91]$ & $\begin{array}{l}\text { multiple cantilever } \\
\text { chips }\end{array}$ & Micro fabrication & $\begin{array}{l}\text { silicon or silicon on } \\
\text { insulator }(\mathrm{SOI})\end{array}$ & & \\
\hline Jenkins et al [92] & SOI wafer & MEMS technology & $\begin{array}{l}\text { thick bottom layer } \\
\text { with single crystal } \\
\text { silicon, middle layer } \\
\text { with silicon oxide } \\
\text { and top layer with } \\
\text { single crystal } \\
\text { silicon or silicon } \\
\text { nitride }\end{array}$ & & \\
\hline Hierlemann et al [88] & cantilever & CVD & $\begin{array}{l}\text { silicon oxide and } \\
\text { silicon nitride }\end{array}$ & & \\
\hline Hierlemann et al [88] & cantilever & PVD & gold & alkanethiols & \\
\hline $\mathrm{Hu} \mathrm{Z}$ et al [101] & cantilever & & palladium & hydrogen & $\begin{array}{l}\text { reported bulk adsorption with differential } \\
\text { stress formation which leads to film } \\
\text { expansion }\end{array}$ \\
\hline Balselt et al [102] & $\begin{array}{l}\text { array of } 10 \\
\text { micromachined } \\
\text { cantilever beams. }\end{array}$ & MEMS technology & $90 \% \mathrm{Pd}$ and $10 \% \mathrm{Ni}$ & Hydrogen & detect concentrations of $0.4 \%$ hydrogen \\
\hline Fabre et al [103] & $\begin{array}{l}\text { microcantilevers } \\
\text { sensor }\end{array}$ & MEMS technology & $\mathrm{Pd}$ & hydrogen & $\begin{array}{l}\text { Reported that surface stress response } \\
\text { depends strongly on the hydrogen } \\
\text { dissociation into the bulk of the Pd layer }\end{array}$ \\
\hline Zhou et al [105] & $\begin{array}{c}\text { self excited } \\
\text { piezoelectric } \\
\text { microcantilevers }\end{array}$ & & MFI zeolites layer & Freon & concentration of $10 \mathrm{ppm}$ \\
\hline Mertens et al [106] & $\mathrm{Si}_{3} \mathrm{~N}_{4}$ micro-cantilever & & $\mathrm{SiO}_{2}$ & $\mathrm{HF}$ & $\begin{array}{l}\text { Identification range varies from } 0.26 \text { to } 13 \\
\text { ppm }\end{array}$ \\
\hline Kooser et al [107] & $\begin{array}{l}\text { piezoresistive } \\
\text { cantilever }\end{array}$ & & $\begin{array}{l}\text { nickel-containing } \\
\text { polyethylene oxide }\end{array}$ & $\begin{array}{l}\text { carbon } \\
\text { monoxide }\end{array}$ & \\
\hline
\end{tabular}




\begin{tabular}{|c|c|c|c|c|c|}
\hline & & & (PEO) layer & & \\
\hline Porter et al [108] & $\begin{array}{l}\text { piezoresistive } \\
\text { microcantilever }\end{array}$ & & & $\begin{array}{l}\text { Hydrogen } \\
\text { cyanide } \\
\text { (HCN) }\end{array}$ & concentration of $150 \mathrm{ppm}$ \\
\hline Udara et al [109] & $\begin{array}{c}\text { NEMS piezoresistive } \\
\text { cantilever }\end{array}$ & & $\begin{array}{l}\text { Poly-vinyalpyridine } \\
\text { and 6- } \\
\text { mercaptonicotinic } \\
\text { acid }\end{array}$ & $\begin{array}{l}\text { ethanol and } \\
\text { Acetaldehyde }\end{array}$ & $\begin{array}{l}\text { conclude that ethanol with permeable 6- } \\
\text { mercaptonicotinic acid }(6-M N A) \text { nano } \\
\text { cantilever gives better resistance }\end{array}$ \\
\hline Siddaiah et al [110] & $\begin{array}{c}\text { U-shaped and } \\
\text { rectangular MEMS } \\
\text { based triple coupled } \\
\text { cantilevers }\end{array}$ & $\begin{array}{c}\text { COMSOL } \\
\text { Multiphysics }\end{array}$ & & & $\begin{array}{c}\text { U-shaped MEMS cantilever of } 100 \mu \mathrm{m} x \\
20 \mu \mathrm{m} \times 2 \mu \mathrm{m} \text { produces high displacement } \\
\text { and better thermal response }\end{array}$ \\
\hline Hawari et al [111] & $\begin{array}{l}\text { Proposed Various } \\
\text { MEMS based } \\
\text { microcantilevers } \\
\text { shapes }\end{array}$ & $\begin{array}{l}\text { ANSYS simulation } \\
\text { software }\end{array}$ & & & $\begin{array}{c}\text { Reported that } \\
\text { trapezoidal design microcantilever would } \\
\text { have significant sensing advantages } \\
\text { compared to other remaining } \\
\text { microcantilever shape }\end{array}$ \\
\hline
\end{tabular}

\section{CONCLUSION}

In this paper the prime intend was made on exploring and studying different gas sensing solution, especially designed as Cantilever MEMS models. Considering efficiency and sensitivity of cantilever sensor, the predominant focus was made on assessing different factors impacting overall performance or scope for further optimization. This manuscript revealed that though cantilever MEMS can be a suitable solution for gas sensor purpose, its optimal design, especially in conjunction with shape, size, surface coating material is must. Though, different researches have been made towards cantilever sensor design, majority of the models either employ cantilever sensor as standalone solution, which seems limited under multiple gas environment. This study revealed that the optimal balance between semiconducting materials and structural design can enable optimal gas sensing. It has been found that the design, shape and materials of the cantilever MEMS can have the impact on overall performance however selecting the optimal set of variables (i.e., shape, size, coating material etc) is complex problem, which can also be called as NP-hard problem. Undeniably, solving such problem can enable designing a robust cantilever-MEMS sensor for gas detection. To solve it, machine learning methods, or reinforcement learning concepts can be applied. Structurally, the optimal setup with Piezo-resistive cantilever MEMS with optimal shape, size and coating material can enable optimal gas sensing performance of the micro-cantilever structure. Moreover, the selection of coating materials can help achieving deflection sensing or surface strain to perform flow rate assessment.

\section{REFERENCE}

[1] G. Schiavone, A. S. Bunting, M. P. Y. Desmulliez and A. J. Walton, "Fabrication of Electrodeposited Ni-Fe Cantilevers for Magnetic MEMS Switch Applications," in Journal of Microelectromechanical Systems, vol. 24, no. 4, pp. 870-879, Aug. 2015.

[2] S. Kedia and W. Wang, "Simulation, Design, Fabrication, and Testing of a MEMS Resettable Circuit Breaker," in Journal of Microelectromechanical Systems, vol. 24, no. 1, Feb.2015.

[3] S. Saxena, R. Sharma and B. D. Pant, "Design and development of cantilever-type MEMS based piezoelectric energy harvester," 2015 19th International Symposium on VLSI Design and Test, Ahmedabad,2015.

[4] C. Tassetti et al., "Gas detection and identification using MEMS TOF mass spectrometer," 2013 Transducers \& Eurosensors XXVII: The 17th International Conference on Solid-State Sensors, Actuators and Microsystems, Barcelona, 2013.

[5] S. Nabavi and L. Zhang, "Design and optimization of MEMS piezoelectric energy harvesters for improved efficiency," 2017 IEEE SENSORS, Glasgow, 2017.

[6] K. Demirel, E. Yazgan, Ș. Demir and T. Akın, "A New TemperatureTolerant RF MEMS Switch Structure Design and Fabrication for KaBand Applications," in Journal of Microelectromechanical Systems, vol. 25, no. 1, Feb. 2016.

[7] Z. Wu and M. Rais-Zadeh, "A Temperature-Stable Piezoelectric MEMS Oscillator Using a CMOS PLL Circuit for Temperature Sensing and Oven Control," in Journal of Microelectromechanical Systems, vol. 24, no. 6, Dec. 2015

[8] R. Dahle and R. Rasel, "3-D Printing as an Effective Educational Tool for MEMS Design and Fabrication," in IEEE Transactions on Education, vol. 59, no. 3, Aug. 2016.

[9] Jian Lu, Yi Zhang, T. Itoh and R. Maeda, "Design, fabrication, and integration of piezoelectric MEMS devices for applications in wireless sensor network," 2011 Symposium on Design, Test, Integration \& Packaging of MEMS/MOEMS (DTIP), Aix-en-Provence, 2011.

[10] R. G. Azevedo et al., "Silicon carbide coated MEMS strain sensor for harsh environment applications," 2007 IEEE 20th International Conference on Micro Electro Mechanical Systems (MEMS), Hyogo, pp. 643-646, 2007.

[11] J. Zhu, M. Palla, S. Ronca, R. Warpner, J. Ju and Q. Lin, "A MEMS based approach to detection of single nucleotide polymorphisms for genetic disorder diagnosis," 2012 IEEE 25th International Conference on Micro Electro Mechanical Systems (MEMS), Paris, 2012.

[12] Jack Chou, "Electrochemical," Hazardous Gas Monitors: A Practical Guide to Selection, Operation and Applications, Chapter 2, (2000), 2834. http://www.intlsensor.com/pdf/electrochemical.pdf

[13] A. D. McNaught and A. Wilkinson, IUPAC Compendium of Chemical Terminology, 2nd ed. Cambridge, U.K.: Royal Society Chemistry.

[14] C.-C. Liu, "Applications of microfabrication techniques in electrochemical sensor development," Applied biochemistry and biotechnology, vol. 41, pp. 99-107, 1993

[15] S. Udina, A. Pardo, S. Marco, J. Santander and L. Fonseca, "Thermoelectric MEMS sensors for natural gas analysis," SENSORS, 2008 IEEE, Lecce, 2008.

[16] S. Ke and C. Shen, "Fe3O4 magnetic enhanced CMOS MEMS compatible gas sensor," 2013 IEEE International Conference of IEEE Region 10 (TENCON 2013), Xi'an, 2013.

[17] Srinivasarao Udara, Hadimani H C, Harish H M and Yedukondalu Udara, " Fabrication of Piezoresistive MEMS/NEMS Nano Material Coated Cantilever and Their Resistance Response Based on Analytes Using OmniCant Experimentation", International Journal of Engineering and Manufacturing Science, Volume 8, Number 2018 pp. 151-157.

[18] J. W. Gardner and P. N. Bartlett, 'Pattern Recognition in Gas Sensing', in P. T. Moseley, J. 0. W. Norris and D. E. Williams, Techniques an Mechanisms in Gas Sensing, Adam Hilger, Bristol, (1991). 
[19] D. Ying, G. Wei and Y. Zheng, "Direct bonding SOI Wafer based MEMS cantilever resonator for trace gas sensor applicaiton," 2009 4th IEEE International Conference on Nano/Micro Engineered and Molecular Systems, Shenzhen, 2009.

[20] F. Zee and J. Judy, "MEMS chemical gas sensor," Proceedings of the Thirteenth Biennial University/Government/Industry Microelectronics Symposium Minneapolis, MN, USA, pp. 150-152, 1999.

[21] M. G. El-Din and W. Moussa, "ANN modeling of micro-machined gas sensor signals," 2005 International Conference on MEMS,NANO and Smart Systems, Banff, Alta., Canada, 2005.

[22] X. Yu, Y. Tang, H. Zhang, T. Li and W. Wang, "Design of HighSensitivity Cantilever and Its Monolithic Integration With CMOS Circuits," in IEEE Sensors Journal, vol. 7, no. 4,April2007.

[23] Gupta, J. P. Denton, H. McNally and R. Bashir, "Novel fabrication method for surface micromachined thin single-crystal silicon cantilever beams," in Journal of Microelectromechanical Systems, vol. 12, no. 2, pp. 185-192, April 2003.

[24] C. S. Lee, W. H. Jin, H. J. NAm, S. M. Cho, Y. S. Kim and J. U. Bu, "Micro cantilevers with integrated heaters and piezoelectric detectors for low power SPM data storage application," The Sixteenth Annual International Conference on Micro Electro Mechanical Systems, 2003. MEMS-03Kyoto.IEEE,Kyoto,Japan,pp.28-32,2003.

[25] B. Tian, H. Li, N. Yang, H. Liu and Y. Zhao, "A MEMS-based flow sensor with membrane cantilever beam array structure," 2017 IEEE 12th International Conference on Nano/Micro Engineered and Molecular Systems (NEMS), Los Angeles, CA, pp. 185-189, 2017.

[26] R.E. Shaffer, S.L. Rose-Pehrsson, R.A. McGill, Anal. Chim. Acta. 384 (1999) 305

[27] Lawrence, 'Introduction to Neural Networks', California Scientific Software Press, Nevada City, (1994)

[28] G. Lammel, S. Schweizer and P. Renaud, "MEMS infrared gas spectrometer based on a porous silicon tunable filter," Technical Digest. MEMS 2001. 14th IEEE International Conference on Micro Electro Mechanical Systems (Cat. No.01CH37090), Interlaken, Switzerland, 2001

[29] Wu Pan and Ning Li, "Micro-cantilever array and its application in gas sensor," 2008 International Conference on Microwave and Millimeter Wave Technology, Nanjing, pp. 1547-1550, 2008.

[30] S. Ghosh, S. Chatterjee, A. Kundu, S. Maity and H. Saha, "Thermal analysis of cantilever MEMS based Low power microheater array for the selective detection of explosive and toxic gases," 2012 1st International Symposium on Physics and Technology of Sensors, Pune,pp.90-293,2012.

[31] D. F. Wang, D. Zhou, S. Liu and J. Hong, "Quantitative Identification Scheme for Multiple Analytes With a Mode-Localized Cantilever Array," in IEEE Sensors Journal, vol. 19,,15Jan.15,2019.

[32] J. Thaysen, R. Marie and A. Boisen, "Cantilever-based bio-chemical sensor integrated in a microliquid handling system," Technical Digest MEMS 2001. 14th IEEE International Conference on Micro Electro Mechanical Systems (Cat No.01CH37090), Interlaken, Switzerland, pp. 401-404, 2001.

[33] Kenda, M. Kraft, C. Wagner, B. Lendl and A. Wolter, "MEMS-based spectrometric sensor for the measurement of dissolved CO2," SENSORS, 2008 IEEE, Lecce, 2008.

[34] P. G. Datskos, N. V. Lavrik, M. J.Sepaniak and P. Dutta, "Chemical Sensors Based on Funstionalized Microcantilever Arrays," SENSORS, 2006 IEEE, Daegu, 2006.

[35] M. Chen, S. Peng, N. Wang, L. Xu, F. Lin and F. Wu, "A Wide-Range and High-Resolution Detection Circuit for MEMS Gas Sensor," in IEEE Sensors Journal, vol. 19, no. 8, pp. 3130-3137, 15 April15, 2019.

[36] P. G. R. Smith, P. A. Cooper, J. C. Gates, C. Holmes, L. G. Carpenter and P. L. Mennea, "Silica MEMS cantilever arrays," 2015 International Conference on Photonics in Switching (PS), Florence, 2015, pp. 333335 .

[37] Y. Wu, J. Wang, X. Zhang, C. Zhang and G. Ding, "Modeling of a bistable MEMS mechanism with torsion/cantilever beams," 2010 IEEE 5th International Conference on Nano/Micro Engineered and Molecular Systems, Xiamen, 2010.
[38] K. A. A. Wahib, Y. Wahab, A. Y. M. Shakaff and S. Saadon, "Array design consideration of the MEMS vibration energy harvester cantilever based structure: Top proof mass vs back etch mass vs interdigitated electrode design," 2015 IEEE Student Symposium in Biomedical Engineering \& Sciences (ISSBES), Shah Alam, pp. 64-69, 2015.

[39] Zunxian Yang, Xinxin Li, Yuelin Wang, Min Liu, HaifeiBao and Baoluo Cheng, "Micro cantilever probe array with integration of electro-thermal nano tip and piezoresistive sensor," SENSORS, 2003 IEEE, Toronto, Ont., pp. 830-833 Vol.2,2003.

[40] Ashish and T. Shanmuganantham, "A micromachined cantilever based flow rate and flow direction sensing scheme," 2014 International Conference on Communication and Signal Processing, Melmaruvathur, 2014

[41] N. Kalaiyazhagan and T. Shanmuganantham, "Performance analysis of MEMS cantilever sensor for agriculture applications," 2017 IEEE International Conference on Circuits and Systems (ICCS), Thiruvananthapuram, 2017, pp.

[42] A. Nallathambi and T. Shanmuganantham, "Performance analysis of cantilever based MEMS sensor for environmental applications," 2014 International Conference on Smart Structures and Systems (ICSSS), Chennai, 2014.

[43] X. Li, D. Zhou, J. He, X. Liu and D. F. Wang, "Mode-localized cantilever array for picogram order mass sensing," 2017 IEEE 12th International Conference on Nano/Micro Engineered and Molecular Systems (NEMS), Los Angeles, CA, 2017.

[44] P. N. Patel, R. Yadav and M. Adhvaryu, "Design and analysis of diversified micro-cantilever structure for sensor applications," 2014 2nd International Conference on Emerging Technology Trends in Electronics, Communication and Networking, Surat, 2014, pp. 1-5.

[45] S. M. Firdaus, I. A. Azid, O. Sidek, K. Ibrahim and MagdyHussien, "Half cut stress concentration (HCSC) region design on MEMS piezoresistive cantilever for sensitivity enhancement," 2008 33rd IEEE/CPMT International Electronics Manufacturing Technology Conference (IEMT), Penang, pp. 1-6, 2008.

[46] M. Villarroya et al., "Cantilever based MEMS for multiple mass sensing," Research in Microelectronics and Electronics, $2005 \mathrm{PhD}$ Lausanne, Switzerland, 2005, pp. 197-200 vol.1.

[47] K. Said, H. Alun and B. Jim, "Testing and characterization of a MEMS micro-cantilever system," 2016 IEEE 59th International Midwest Symposium on Circuits and Systems, Abu Dhabi, pp. 1-4, 2016.

[48] Yu Xiaomei, Zhang Dacheng, Wang Wei and Li Ting, "A sensor platform based on piezoresistive cantilever," 2003 IEEE Conference on Electron Devices and Solid-State Circuits (IEEE Cat. No.03TH8668), Hong Kong, China, pp. 121-124, 2003

[49] M. Possas et al., "Frequency profile measurement system for microcantilever-array based gas sensor," 2015 Symposium on Design, Test, Integration and Packaging of MEMS/MOEMS (DTIP), Montpellier, 2015

[50] W. Ting, Z. Wenjie, Y. Yang and S. Yunbo, "The On-Line Detection System of Gas Mixture Based on LabVIEW and MEMS Sensor Arrays," 2014 Fourth International Conference on Instrumentation and Measurement, Computer, Communication and Control, Harbin, 2014.

[51] Y. Zhang, A. Toda, H. Okada, T. Kobayashi, T. Itoh and R. Maeda "New wafer-scale MEMS fabrication of 3D silicon/metal cantilever array sensor," 2012 IEEE 25th International Conference on Micro Electro Mechanical Systems (MEMS), Paris, 2012, pp. 297-300.

[52] N. A. Djuzhev, D. V. Novikov, G. D. Demin, A. I. Ovodov and V. T. Ryabov, "An experimental study on MEMS-based gas flow sensor for wide range flow measurements," 2018 IEEE Sensors Applications Symposium (SAS), Seoul, 2018

[53] Fengli Liu, YongpingHao, Xing Wang and Mahui Xu, "A MEMS Xtype plane micro-cantilever stiffness research," Proceeding of the 11th World Congress on Intelligent Control and Automation, Shenyang, 2014.

[54] S. Priyadarsini, J. K. Das and A. Dastidar, "Analysis of MEMS cantilever geometry for designing of an array sensor," 2016 International Conference on Signal Processing, Communication, Power and Embedded System (SCOPES), Paralakhemundi, 2016.

[55] B. Tian, H. Li, N. Yang, H. Liu and Y. Zhao, "A MEMS-based flow sensor with membrane cantilever beam array structure," 2017 IEEE 
12th International Conference on Nano/Micro Engineered and Molecular Systems (NEMS), Los Angeles, CA, pp. 185-189, 2017.

[56] S. Z. Lulec et al., "Simultaneous self-sustained actuation and parallel readout with MEMS cantilever sensor array," 2012 IEEE 25th International Conference on Micro Electro Mechanical Systems (MEMS), Paris, 2012.

[57] P. Prakash et al., "Optical read-out scheme based on grated waveguide cantilever cavity resonance for interrogation of cantilever sensor arrays," COMMAD 2012, Melbourne, VIC, pp. 69-70, 2012.

[58] G. Putrino, A. Keating, M. Martyniuk, L. Faraone and J. M. Dell, "A novel optical read-out technology for large arrays of micromachined cantilever sensors," 2011 International Quantum Electronics Conference (IQEC) and Conference on Lasers and Electro-Optics (CLEO) Pacific Rim incorporating the Australasian Conference on Optics, Lasers and Spectroscopy and the Australian Conference on Optical Fibre Technology, Sydney, NSW, pp. 2039-2041,2011.

[59] V. Litovski, M. Andrejevic and M. Zwolinski, "ANN based modeling, testing and diagnosis of MEMS [capacitive pressure transducer example]," 7th Seminar on Neural Network Applications in Electrical Engineering, 2004. NEUREL 2004. 2004, Belgrade, Serbia, 2004.

[60] M. Engesser, A. Buhmann, A. R. Franke and J. G. Korvink, "Efficient Reliability-Based Design Optimization for Microelectromechanical Systems," in IEEE Sensors Journal, vol. 10, no. 8, Aug. 2010

[61] R.J. Wilfinger, P.H. Bardell, D.S. Chhabra: The Resonistor, a frequency sensitive device utilizing the mechanical resonance of a silicon substrate, IBM J. Res. Div. 12, 113-118 (1968).

[62] T.M.S. Heng: Trimming of microstrip circuits utilizing microcantilever air gaps, IEEE Trans. Microw. Theory Technol. 19, 652-654 (1971)

[63] K.E. Petersen: Micromechanical membrane switches on silicon, IBM J. Res. Develop. 23, 376-385 (1979)

[64] E.S. Kolesar: Electronic Nerve Agent Detector, United States Patent 4549427 (1983), filed Sep. 19

[65] H.P. Lang, R. Berger, C. Andreoli, J. Brugger, M. Despont, P. Vettiger, Ch. Gerber, J.K. Gimzewski, J.- P. Ramseyer, E. Meyer, H.-J. Güntherodt: Sequential position readout from arrays of micromechanical cantilever sensors, Appl. Phys. Lett. 72, 383-385 (1998)

[66] G. Binnig, C.F. Quate, C. Gerber: Atomic force microscope, Phys. Rev. Lett. 56, 930-933 (1986)

[67] T. Itoh, T. Suga: Force sensing microcantilever using sputtered zincoxide thin-film, Appl. Phys. Lett. 64, 37-39 (1994)

[68] J.P. Cleveland, S. Manne, D. Bocek, P.K. Hansma: A nondestructive method for determining the spring constant of cantilevers for scanning force microscopy, Rev. Sci. Instrum. 64, 403-405 (1993)

[69] T. Thundat, R.J. Warmack, G.Y. Chen, D.P. Allison: Thermal and ambient-induced deflections of scanning force microscope cantilevers, Appl. Phys. Lett. 64, 2894-2896 (1994)

[70] J.K. Gimzewski, Ch. Gerber, E. Meyer, R.R. Schlittler: Observation of a chemical reaction using a micromechanical sensor, Chem. Phys. Lett. 217, 589-594 (1994)

[71] T. Thundat, G.Y. Chen, R.J. Warmack, D.P. Allison, E.A. Wachter: Vapor detection using resonating microcantilevers, Anal. Chem. 67, 519-521 (1995)

[72] H. Ibach: Adsorbate-induced surface stress, J. Vac. Sci. Technol. A 12 2240-2245 (1994)

[73] R. Berger, E. Delamarche, H.P. Lang, C. Gerber, J.K. Gimzewski, E. Meyer, H.-J. Güntherodt: Surface stress in the self-assembly of alkanethiols on gold, Science 276, 2021-2024 (1997).

[74] R. Berger, H.P. Lang, C. Gerber, J.K. Gimzewski, J.H. Fabian, L. Scandella, E. Meyer, H.-J. Güntherodt: Micromechanical thermogravimetry, Chem. Phys. Lett. 294, 363-369 (1998).

[75] T. Bachels, F. Tiefenbacher, R. Schafer: Condensation of isolated metal clusters studied with a calorimeter, J. Chem. Phys. 110, 10008-10015 (1999)

[76] J.R. Barnes, R.J. Stephenson, C.N. Woodburn, S.J. O'Shea, M.E Welland, T. Rayment, J.K. Gimzewski, C. Gerber: A femtojoule calorimeter using micromechanical sensors, Rev. Sci. Instrum. 65, 3793-3798 (1994).
[77] Possas, M.; Rousseau, L.; Ghassemi, F.; Lissorgues, G.; Scorsone, E.; Bergonzo, P. Fabrication and micromechanical characterization of polycrystalline diamond microcantilevers. In Proceedings of the 2014 Symposium on Design, Test, Integration and Packaging of MEMS/MOEMS (DTIP), Cannes, France, 1-4 April 2014; pp. 1-5.

[78] Manai, R.; Scorsone, E.; Rousseau, L.; Ghassemi, F.; Abreu, M.P.; Lissorgues, G.; Tremillon, N.; Ginisty, H.; Arnault, J.; Tuccori, E.; et al. Grafting odorant binding proteins on diamond bio-MEMS. Biosens. Bioelectron. 2014, 60, 311-317.

[79] Fritz, J.; Baller, M.; Lang, H.; Rothuizen, H.; Vettiger, P.; Meyer, E.; Güntherodt, H.J.; Gerber, C.; Gimzewski, J. Translating biomolecular recognition into nanomechanics. Science 2000, 288, 316-318.

[80] Arntz, Y.; Seelig, J.D.; Lang, H.; Zhang, J.; Hunziker, P.; Ramseyer, J.; Meyer, E.; Hegner, M.; Gerber, C. Label-free protein assay based on a nanomechanical cantilever array. Nanotechnology 2002, 14, 86.

[81] Thundat, T.;Wachter, E.; Sharp, S.;Warmack, R. Detection of mercury vapor using resonating microcantilevers. Appl. Phys. Lett. 1995, 66, 1695-1697.

[82] Baselt, D.; Fruhberger, B.; Klaassen, E.; Cemalovic, S.; Britton, C.; Patel, S.; Mlsna, T.; McCorkle, D.; Warmack, B. Design and performance of a microcantilever-based hydrogen sensor. Sens. Actuators B Chem. 2003, 88, 120-131.

[83] Maira Possas-Abreu, Farbod Ghassemi, Lionel Rousseau, Emmanuel Scorsone, Emilie Descours and Gaelle Lissorgues, "development of diamond and silicon mems sensor arrays with integrated readout for vapor detection", Sensors 2017. pp. 1-15

[84] Yu-Hsiang Wang, Chia-Yen Lee and Che-Ming Chiang, "A MEMS based Air Flow Sensor with a Free-standing Microcantilever Structure, Sensors 2007, pp. 2389-2401.

[85] Chatzandroulis, S.; Tserepi, A.; Goustouridis, D.; Normand, P.; Tsoukalas, D. Microelectron. Eng. 2002, 61-62, 955.

[86] Mertens, J.; Alvarez, M.; Tamayo, J. Appl. Phys. Lett. 2005, 87 , 234102/1

[87] Plaza, J. A.; Zinoviev, K.; Villanueva, G.; Alvarez, M.; Tamayo, J Dominguez, C.; Lechuga, L. M. Appl. Phys. Lett. 2006, 89, 094109

[88] Hierlemann, A.; Brand, O.; Hagleitner, C.; Baltes, H. Proc. IEEE 2003, $91,839$.

[89] Madou, M. Fundamentals of Microfabrication: The Science of Miniaturization, second ed.; CRC Press: Boca Raton, FL, 2002.

[90] Jastrzebski, L.; Corboy, J. F.; Soydan, R. J. Electrochem. Soc. 1989 $136,3506$.

[91] Jastrzebski, L.; Corboy, J. F.; McGinn, J. T.; Pagliaro, R., Jr. J. Electrochem. Soc. 1983, 130, 1571.

[92] Jenkins, N. E.; DeFlores, L. P.; Allen, J.; Ng, T. N.; Garner, S. R.; Kuehn, S.; Dawlaty, J. M.; Marohn, J. A. J. Vac. Sci. Technol., B 2004, $22,909$.

[93] Karen M. Goeders, Jonathan S. Colton and Lawrence A. Bottomley, “ Microcantilevers: Sensing Chemical Interactions via Mechanical Motion", Chem. Rev. 2008, 108, pp. 522-542.

[94] Jiguet, S.; Bertsch, A.; Hofmann, H.; Renaud, P. AdV. Eng. Mater 2004, 6, 719.

[95] Curran, S.; Ajayan, P. M.; Blau, W.; Carroll, D. L.; Coleman, J. N.; Dalton, A.; Davey, A. P.; McCarthy, B. AdV. Mater. 1998, 10, 1091.

[96] Calleja, M.; Nordstroem, M.; Alvarez, M.; Tamayo, J.; Lechuga, L. M.; Boisen, A. Ultramicroscopy 2005, 105, 215.

[97] Calleja, M.; Tamayo, J.; Nordstrom, M.; Boisen, A. Appl. Phys. Lett. 2006, 88.

[98] Ransley, J. H. T.; Watari, M.; Sukumaran, D.; McKendry, R. A.; Seshia, A. A. Microelectron. Eng. 2006, 83, 1621.

[99] Johansson, A.; Calleja, M.; Rasmussen, P. A.; Boisen, A. Sens Actuators, A 2005, A123-A124, 111

[100]Johansson, A.; Blagoi, G.; Boisen, A. Appl. Phys. Lett. 2006, 89 173505

[101] Hu Z, Thundat T, Warmack RJ (2001) Investigation of adsorption and adsorption-induced stresses using microcantilever sensors. J Appl Phys 90:427-431.

[102] Balselt DR, Fruhberger B, Klassen E, Cemalovic S, Britton Jr CL, Patel SV, Mlsna TE, McCorkle D, Warmack B (2003) Design and 
performance of a microcantilever-based hydrogen sensor. Sens Act B 88:120-131.

[103]Fabre A, Finot E, Demoment J, Contreras S (2002) Monitoring the chemical changes in $\mathrm{Pd}$ induced by hydrogen absorption using microcantilevers. Ultramicroscopy 97:425-432.

[104] Ono T, Li X, Miyashita H, Esashi M (2003) Mass sensing of adsorbed molecules in sub-picogram sample with ultrathin silicon resonator. Rev Sci Instrum 74:1240-1243.

[105]Zhou J, Li P, Zhang S, Huang Y, Yang P, Bao M, Ruan G (2003) Self excited piezoelectric microcantilever for gas detection. Microelectr Eng 69:37-46.

[106] Mertens J, Finot E, Nadal MH, Eyraud V, Heintz O, Bourillot E (2003) Detection of gas trace of hydrofluoric acid using microcantilever. Sens Act B 99:58-65.

[107]Kooser A, Gunter RL, Delinger WD, Porter TL, Eastman MP (2004) Gas sensing using embedded piezoresistive microcantilever sensors. Sens Act B 99:474-479.

[108]Porter TL, Vail TL, Eastman MP, Stewart R, Reed J, Venedam R, Delinger W (2007) A solid-state sensor platform for the detection of hydrogen cyanide gas. Sens Act B 123:313-317.

[109] Srinivasarao Udara, Hadimani H C and Harish H M3, "Yedukondalu Udara4Fabrication of Piezoresistive MEMS/NEMS Nano Material Coated Cantilever and Their Resistance Response Based on Analytes Using OmniCant Experimentation", International Journal of Engineering and Manufacturing Science, Volume 8, Number 1 (2018) pp. 151-157.

[110]N Siddaiah, B Manjusree, A L G N Aditya and D V Rama Koti Reddy, " Design simulation of U-shaped and Rectangular MEMS based tripled coupled cantilevers, Journal of scientific and Industrial Research, vol. 76, 2017, pp. 235-238.

[111]H. F. Hawari, Y. Wahab, M. T. Azmi, A. Y. Md. Shakaff, U. Hashim, S. Johari ,Design and Analysis of Various Microcantilever Shapes for MEMS Based Sensing, ScieTech 2014,Journal of Physics: Conference Series 495 (2014) 012045. 